\title{
PERBANDINGAN FARTLEK DAN SMALL SIDE GAMES UNTUK MENINGKATKAN VO2MAX PADA SISWA EKSTRAKURIKULER
}

\author{
Fajar Dwi Syaroni ${ }^{1 *}$, I Dewa Made Aryananda Wijaya Kusuma ${ }^{2}$ \\ ${ }^{1}$ Jurusan Pendidikan Kepelatihan Olahraga, Universitas Negeri Surabaya, Surabaya, Indonesia \\ ${ }^{2}$ Jurusan Pendidikan Kepelatihan Olahraga, Universitas Negeri Surabaya, Surabaya, Indonesia \\ * fajarsyaroni@mhs.unesa.ac.id
}

(Received: June 2020 / Revised: June 2020 / Accepted: July 2020)

\begin{abstract}
ABSTRAK: Penelitian ini bertujuan untuk membandingakan dua metode latihan yaitu latihan fartlek dan latihan small side games terhadap peningkatan VO2max. Penelitian ini menggunakan metode quasi eksperiment dengan sampel berjumlah 20 orang siswa menggunakan tehnik total sampling. Instrumen pengambilan data menggunakan tes multistage fitness test dengan teknik analisis data paired sample $t$-test dan independent samples $t$-test. Hasil penelitian menunjukkan bahwa pada kelompok fartlek mengalami rata-rata peningkatan VO2max sebesar $1,85 \mathrm{ml} / \mathrm{kg} / \mathrm{mnt}$, pada kelompok small side games mengalami ratarata peningkatan VO2max sebesar $1,95 \mathrm{ml} / \mathrm{kg} / \mathrm{mnt}$. Hasil uji paired t-test menunjukkan nilai 0,91 yang berarti $P>0,05$. Maka dengan demikian tidak terdapat perbedaan peningkatan yang signifikan antara kelompok fartlek dan small side games terhadap peningkatan nilai VO2max. Kesimpulan dari penelitian ini adalah terdapat pengaruh yang signifikan pada latihan fartlek dan small side games terhadap peningkatan VO2max, tidak terdapat perbedaan peningkatan yang signifikan antara latihan fartlek dan latihan small side games terhadap peningkatan $\mathrm{VO} 2 \mathrm{max}$

KATA KUNCl: $\quad$ Futsal, Fartlek, Small Side Games, Vo2max.
\end{abstract}

ABSTRACTS: This study aims to compare two training methods, namely fartlek training and small side games training on VO2max improvement. This study uses a quasi-experimental method with a sample of 20 students using a total sampling technique. Data collection instruments used a multistage fitness test with paired sample t-test and independent samples $t$-test data analysis techniques. The results showed that in the fartlek group experienced an average increase in VO2max of $1.85 \mathrm{ml} / \mathrm{kg} / \mathrm{min}$, in the small side games group experienced an average increase of VO2max of $1.95 \mathrm{ml} / \mathrm{kg} / \mathrm{min}$. Paired t-test results showed a value of 0.91 , which means $P>0.05$. Then there is no significant difference between the fartlek group and small side games to increase VO2max value. The conclusion of this study is that there is a significant effect on fartlek training and small side games on increasing VO2max, there is no significant difference between fartlek training and small side games training on increasing VO2max.

KEYWORD: $\quad$ Futsal, Fartlek, Small Side Games, Vo2max.

\section{PENDAHULUAN}

Futsal dimulai di Montevideo, Uruguy pada tahun 1930, oleh Juan Carlos Ceriani. Diadakan di Amerika Selatan terutama di Brasil (Mulyono, 2017). Tahun 2004 futsal mulai muncul dan berkembang. Futsal merupakan olahraga yang dilakukan oleh 2 tim, 1 tim terdiri dari lima orang dan tujuannya untuk memenangkan bola ke gawang lawan. Anak organisasi futsal di Indonesia sendiri dikenal dengan sebutan FFI (federal futsal Indonesia).
Futsal olahraga yang dimainkan di lapangan maksimal panjang 25-42m dan lebar 15$25 \mathrm{~m}$ dengan waktu $2 \times 20$ menit (Lhaksana, 2011). Menurut (Kusuma, 2019) apabila dilihat dari durasi waktu, ukuran lapangan dan jumlah pemain maka seluruh pemain dituntut memiliki kemampuan daya tahan yang baik. Permainan futsal mengutamakan kemampuan daya tahan aerobik atau Vo2max yang tinggi sangat menjadi kunci utama. Vo2max adalah keseimbangan dimana organ pernafasan manusia untuk mengatur nafas dan menghirup oksigen pada 
waktu latihan (Sukadianto, 2011). Daya tahan jantung paru yang baik, akan membuat atlet tidak mudah mengalami kelelahan terutama cabang olahraga yang durasi waktunya panjang (Satrio \& Winarno, 2019).

Terdapat banyak model latihan untuk meningkatkan daya tahan, menurut (Sukadianto, 2011) di dalam melatih daya tahan atau Vo2max terdapat baberapa latihan, salah satunya yaitu latihan fartlek dan small side game.

Latihan fartlek merupakan bentuk latihan daya tahan aerob yang memuat unsur kecepatan, kekuatan, dan daya tahan aerob sekaligus (Sidik, Pesurnay, \& Afari, 2019). Menurut (Muthu Eleckuvan, 2014) farlek merupakan salahsatu model latihan yang dapat meningkatkan kardiovaskuler.

Small sided games merupakan bentuk latihan yang menggabungkan keterampilan gerak khusus cabang olahraga dan intensitas yang tinggi (Halouani, Chtourou, Gabbett, Chaouachi, \& Chamari, 2014). Menurut (Owen, Twist, \& Ford, 2004) dengan mengalami situasi yang sebenarnya selama latihan, pemain dapat meningkatkan aspek teknis, taktis, dan fisiologis permainan mereka.

Dari uraian diatas bahwa setiap pemain futsal dituntut harus mempunyai daya tahan atau Vo2max yang bagus, dan dalam melatih daya tahan diperlukan bermacam macam bentuk latihan yang bisa memaksimalkan daya tahan para pemain, salah satunya adalah dengan latihan fartlek dan small side games. Dari kedua bentuk latihan ini akan ada salah satu bentuk latihan yang sangat berpengaruh terhadap daya tahan atau Vo2max. Maka dari itu peneliti ingin mencoba menerapkan kedua bentuk latihan tersebut untuk mengetahui latihan manakah yang sangat berpengaruh terhadap daya tahan atau Vo2max di ekstrakulikuler futsal SMAN 1 MOJOSARI.

\section{METODE PENELITIAN}

Jenis yang digunakan adalah metode eksperimen semu dengan desain penelitian berupa two group pre-test post-test. Menurut (Mahardika, 2015) metode eksperimen semu merupakan metode yang tidak menggunakan control dan atau manipulasi semua variable yang relevant. Instrument pengambilan data pada penelitian ini menggunakan Multistage Fitness Test (MFT) (Castagna, Impellizzeri, Manzi, \& Ditroilo, 2010). MFT merupakan salah satu bentuk tes kebugaran yang digunakan untuk mengukur Vo2max atau penyerapan oksigen maksimal seorang atlet.

Penelitian ini dialakukan pada siswa extrakulikuler futsal dengan jumlah sampel 20 atlet, dibagi menjadi 2 kelompok yaitu 10 atlet melakukan treatment fartlek dan 10 atlet melakukan treatment small side games.

Tahap awal peneliti melakukan pre-test sebagai pengambilan data awal dengan menggunakan instrument $\mathrm{mft}$ dengan lari jarak $20 \mathrm{~m}$ bolak-balik, setelah mengambil data awal dibentuk menjadi 2 kelompok kemudian diberi perlakuan treatment latihan fartlek seperti jogging,sprin, dan jalan kemudian latihan small side games dengan 5 lawan 5 dilakuakan selama 6 minggu dengan frekuensi 3 kali latihan dalam satu minggu, setelah melakukan treatment selama 6 minggu diberi perlakuan post-test untuk mengetahui data akhir.

\section{HASIL}

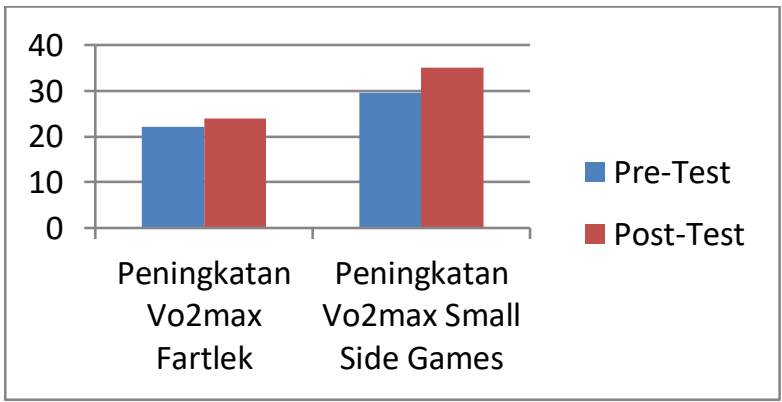

Grafik 1. Peningkatan Vo2max 
Berdasarkan data grafik 1 menjelaskan bahwa Vo2max latihan fartlek pada saat pre-test yaitu $22,1 \mathrm{ml} / \mathrm{kg} / \mathrm{mnt}$ setelah diberi perlakuan treatment selama 6 minggu dan dilakukan posttest yaitu $23,9 \mathrm{ml} / \mathrm{kg} / \mathrm{mnt}$ dalam latihan tersebut meningkatnya Vo2max sebesar $1,8 \mathrm{ml} / \mathrm{kg} / \mathrm{mnt}$. Sedangkan dalam latihan small side games Vo2max pada saat pre-test yaitu $29,5 \mathrm{ml} / \mathrm{kg} / \mathrm{mnt}$ setelah diberi perlakuan treatment selama 6 minggu dan dilakukan post-test yaitu 35,0 $\mathrm{ml} / \mathrm{kg} / \mathrm{mnt}$ dalam latihan tersebut meeningkatnya Vo2max sebesar $5,5 \mathrm{ml} / \mathrm{kg} / \mathrm{mnt}$. Maka dapat diambil kesimpulan bahwa terjadi peningkatan Vo2max pada saat sebelum dan sesudah dilakukan treatment. Pada saat sebelum diberikan perlakuan menunjukan hasil Vo2maxnya rendah, dan setelah diberikannya perlakuan treatment selama 6 minggu dengan frekuensi 3kali dalam 1 minggu terjadi peningkatan yang sanagat baik terhadap Vo2maxnya.

Tabel 1. Rata-Rata Vo2max Kelompok Fartlek

\begin{tabular}{lccccc}
\hline & $\mathrm{N}$ & Min & $\begin{array}{c}\text { Ma } \\
\mathrm{x}\end{array}$ & $\begin{array}{c}\text { Mea } \\
\mathrm{n}\end{array}$ & $\begin{array}{c}\text { Std. } \\
\text { Deviation }\end{array}$ \\
\hline pre_fartl & 1 & 22. & 45.20 & 33.96 & 6.17580 \\
$e k$ & 0 & 10 & & 00 & \\
\hline post_fartl & 1 & 23. & 46.80 & 35.81 & 5.89094 \\
$e k$ & 0 & 90 & & 00 & \\
\hline Valid N & 1 & & & & \\
(listwise) & 0 & & & & \\
\hline
\end{tabular}

Pada tabel 1 tersebut menampilkan data tentang rata-rata pre-test dan post-test pada kelompok yang melakukan latihan fartlek.

Tabel 2. Uji Pengaruh Kelompok Fartlek

\begin{tabular}{|c|c|c|c|c|c|c|c|c|}
\hline & $\begin{array}{r}P a \\
\text { Diffe }\end{array}$ & $\begin{array}{l}\text { Paired } \\
\text { erenc }\end{array}$ & & & & \multirow{3}{*}{$\mathbf{T}$} & \multirow{3}{*}{$\begin{array}{l}D \\
f\end{array}$} & \multirow{3}{*}{$\begin{array}{l}\text { Sig } \\
(2- \\
\text { tai } \\
\text { ed }\end{array}$} \\
\hline & \multirow[t]{2}{*}{ Mean } & \multicolumn{2}{|c|}{$\begin{array}{l}\text { Std. Std. } \\
\text { Devi Erro }\end{array}$} & \multicolumn{2}{|c|}{$\begin{array}{c}95 \% \\
\text { Confidence } \\
\text { Interval of the } \\
\text { Difference } \\
\end{array}$} & & & \\
\hline & & & n & Lower & Upper & & & \\
\hline Pair & - & 1.46 & .462 & - & -.80339 & -3.999 & 99 & .003 \\
\hline 1pre fartlek & 1.85 & 306 & 66 & 2.896 & & & & \\
\hline- & 000 & & & 61 & & & & \\
\hline post_fartlek & & & & & & & & \\
\hline
\end{tabular}

Data yang telah ditampilkan oleh tabel 2 merupakan data yang diperoleh setelah melalui uji pengaruh dengan menggunakan paired Page | 39 sample t-test. Pada tabel tersebut menguji pegaruh latihan fartlek terhadap peningkatan nilai VO2max. Data dikatakan memiliki pengaruh yang signifikan jika nilai $P<0,05$. Berdasarkan data tersebut nilai sig (2-tailed) sebsear 0,003 yang berarti bahwa $P<0,05$. Maka dengan demikian dapat dikatakan bahwa terdapat pengaruh yang signifikan pada latihan fartlek terhadap peningkatan VO2max.

Tabel 3. Rata-Rata Vo2max Kelompok Small Side Games

\begin{tabular}{cccccc}
\hline & N & Min & Max & Mean & $\begin{array}{c}\text { Std. } \\
\text { Deviation }\end{array}$ \\
\hline $\begin{array}{c}\text { pre_small } \\
\text { side games }\end{array}$ & 10 & 29.50 & 40.50 & 34.2600 & 4.10127 \\
\hline $\begin{array}{c}\text { post_small } \\
\text { side games }\end{array}$ & 10 & 32.10 & 41.10 & 36.2100 & 3.08381 \\
\hline $\begin{array}{c}\text { Valid N } \\
\text { (listwise) }\end{array}$ & 10 & & & & \\
\hline
\end{tabular}

Pada tabel 3 tersebut menampilkan data tentang rata-rata pre-test dan post-test pada kelompok small side games.

Tabel 4. Uji Pengaruh Kelompok Small Side Games

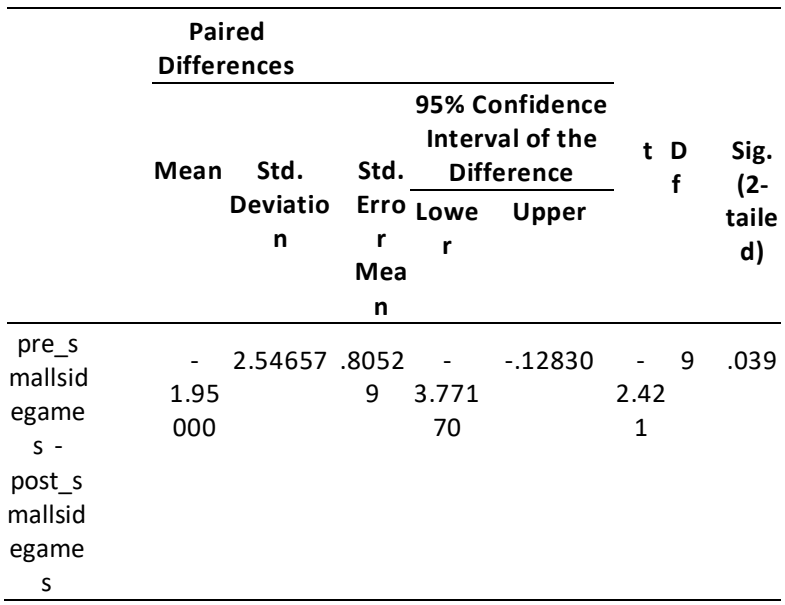

Data yang telah ditampilkan oleh tabel 4 merupakan data yang diperoleh setelah melalui uji pengaruh dengan menggunakan paired sample t-test. Pada tabel tersebut menguji pegaruh latihan fartlek terhadap peningkatan nilai VO2max. Data dikatakan memiliki pengaruh yang signifikan jika nilai $P<0,05$. Berdasarkan data tersebut nilai sig (2-tailed) sebsear 0,003 yang berarti bahwa $P<0,05$. Maka dengan demikian dapat dikatakan bahwa terdapat 
pengaruh yang signifikan pada latihan fartlek terhadap peningkatan VO2max.

Tabel 5. Uji Beda Kelompok Fartlek Dan Small Side Games

\begin{tabular}{|c|c|c|c|c|c|}
\hline $\begin{array}{c}\text { Levene's } \\
\text { Test for } \\
\text { Equality } \\
\text { of } \\
\text { Variances }\end{array}$ & $\begin{array}{r}\text { t-test } \\
\text { of } \\
\end{array}$ & $\begin{array}{l}\text { for Equal } \\
\text { f Means }\end{array}$ & & & \\
\hline \multirow{2}{*}{ F Sig } & \multirow{2}{*}{$\begin{array}{l}\text { Sig. (2- } \\
\text { tailed) }\end{array}$} & \multirow{2}{*}{$\begin{array}{c}\text { Mean } \\
\text { Differe } \\
\text { nce }\end{array}$} & \multirow{2}{*}{$\begin{array}{c}\text { Std. } \\
\text { Error } \\
\text { Differen } \\
\text { ce }\end{array}$} & \multicolumn{2}{|c|}{$\begin{array}{c}95 \% \text { Confidence } \\
\text { Interval of the } \\
\text { Difference }\end{array}$} \\
\hline & & & & Lower & Upper \\
\hline $2.6 \quad .124$ & .915 & .10000 & .92874 & -1.85121 & 2.05121 \\
\hline \multicolumn{6}{|l|}{03} \\
\hline & .916 & .10000 & .92874 & -1.8873 & 2.08730 \\
\hline
\end{tabular}

Berdasarkan data yang telah ditampilkan oleh tabel 5 merupakan tabel yang menampilkan hasil uji beda dengan menggunakan independent samples t-test. Dimana uji tersebut digunakan untuk mengetahui perbedaan antara kedua kelompok. Data dikatakan memiliki perbedaan yang signifikan jikan nilai $P<0,05$. Pada tabel tersebut dijelaskan bahwa nilai sig (2-tailed) memiliki nilai 0,91 yang berarti $P>0,05$. Maka dengan demikian tidak terdapat perbedaan yang signifikan antara kelompok fartlek dan small side games terhadap peningkatan nilai VO2max.

\section{PEMBAHASAN}

Setelah mencermati hasil analisis data yang telah diuraikan pada hasil penelitian tersebut, Penelitian ini memiliki tujuan untuk membandingkan dua jenis latihan yaitu latihan fartlek dan latihan small side games terhadap peningkatan nilai VO2max. Fartlek merupakan olahraga yang biasanya dimulai dengan lari lambat-lambat atau jalan, kemudian divariasikan sprint-sprint pendek dan lari jarak menengah dengan kecepatan tetap cukup tinggi, kemudian diselingi sprint lagi. Dalam penelitian ini, pada latihan pertama berdurasi 10 menit. Pertama melakukan jogging selama 4 menit, kemudian dilanjutkan sprint dengan jarak 60 meter dengan waktu 30 detik, setelah itu jalan selama 1 menit, dilanjutkan lagi jogging selama 4 menit, lalu Page | 40 melakukan sprint lagi selama 30 detik dengan variasi jogging dan sprint dengan memainkan waktu kerja dan istirahat maka dapat merangsang peningkatan kapasitas aerobic. Hal ini sejalan dengan penelitian yang dilakukan oleh (Lim, Kim, Marsh, \& Belfry, 2018) mengatakan bahwa fartlek mampu meningkatkan kapasitas aerobic.

Selain meneliti latihan fartlek penelitian ini membahas latihan small side games terhadap peningkatan VO2max. Dalam Small side games identik dengan latihan berdurasi lama dengan intensitas sedang dan dilakukan secara kontinu. Dalam penelitian ini, small side games dapat meningkatkan kapasitas aerobic, hal itu dapat disebabkan oleh intensitas latihan yang tinggi saat melakukan latihan, pemain dituntut untuk bergerak secara terus menerus dan tidak ada yang diam selama waktu $2 \times 25$ menit. Hal ini dikuatkan oleh pendapat (Köklü \& Alemdaroğlu, 2016) mengungkapkan bahwa latihan small side games efektif dalam meningkatkan kinerja aerobic intensitas tinggi.

Jadi dalam kedua latihan tersebut bahwa sama-sama dapat meningkatkan VO2max. Karena terdapat kesamaan antara program latihan Fartlek dan Small side games dari segi durasi dan intensitas. Jadi tidak terdapat perbedaan yang signifikan dalam kesamaan durasi antara kelompok fartlek dan small side games terhadap peningkatan nilai VO2max.

\section{SIMPULAN DAN REKOMENDASI}

Kesimpulan dari penelitian ini adalah (1) terdapat peningkatan yang signifikan pada latihan fartlek, (2) terdapat peningkatan yang signifikan pada latihan small side games, (3) tidak terdapat perbedaan yang signifikan terhadap peningkatan Vo2max dari kedua metode latihan tersebut.

Berdasarkan kesimpulan diatas maka disarankan oleh para pelatih untuk dapat menggunakan model latihan fartlek dan small 
side games, namun untuk mendapatkan hasil yang sesuai karakteristik permainan futsal dapat menggunakan model small side games.

\section{REFERENSI}

Castagna, C., Impellizzeri, F. M., Manzi, V., \& Ditroilo, M. (2010). The assessment of maximal aerobic power with the multistage fitness test in young women soccer players. Journal of Strength and Conditioning Research.

https://doi.org/10.1519/JSC.0b013e3181d8e $97 \mathrm{a}$

Halouani, J., Chtourou, H., Gabbett, T., Chaouachi, A., \& Chamari, K. (2014). Smallsided games in team sports training: A brief review. Journal of Strength and Conditioning Research.

https://doi.org/10.1519/JSC.0000000000000 564

Köklü, Y., \& Alemdaroğlu, U. (2016). Comparıson of the Heart Rate and Blood Lactate Responses of Different Small Sided Games in Young Soccer Players. Sports. https://doi.org/10.3390/sports4040048

Kusuma, I. D. M. A. W. (2019). The influence of the differences within the preliminary vo2max level on the Tabata training results. Jurnal SPORTIF: Jurnal Penelitian Pembelajaran.

https://doi.org/10.29407/js_unpgri.v5i2.134 90

Lhaksana, J. (2011). Taktik dan Strategi Futsal Modern. Jakarta: BE CHAMPION.

Lim, D. J., Kim, J. J., Marsh, G. D., \& Belfry, G. R. (2018). Physiological resolution of periodic breath holding during heavy-intensity Fartlek exercise. European Journal of Applied Physiology. https://doi.org/10.1007/s00421018-3986-9

Mahardika, I. M. S. (2015). Metodologi Penelitian. Surabaya: Unesa University Press.

Mulyono, M. A. (2017). Buku Pintar Futsal. Jakarta: Anugrah.

Muthu Eleckuvan, R. (2014). Effectiveness of Fartlek Training on Maximum Oxygen Consumption and Resting Pulse Rate. International Journal of Physical Education, Fitness and Sports. https://doi.org/10.26524/14115

Owen, A., Twist, C., \& Ford, P. (2004). Small-Sided

Page | 41
Games: the Physiological and Technical Effect of Altering Pitch Size and Player Numbers. Insight.

Satrio, B., \& Winarno, M. E. (2019). Quality of sports physical fitness extracurricular participants. Jurnal SPORTIF: Jurnal Penelitian Pembelajaran. https://doi.org/10.29407/js_unpgri.v5i2.130 69

Sidik, D. Z., Pesurnay, P. L., \& Afari, L. (2019). Pelatihan Kondisi Fisik. Bandung: PT. Remaja Rosdakarya.

Sukadianto. (2011). Pengantar Teori dan Metodologi Melatih Fisik. Bandung: CV. Lubuk Agung. 